\title{
COMPOSIÇÃO QUÍMICA DE GRÃOS CRUS DE CULTIVARES DE Coffea arabica L. SUUSCETÍVEIS E RESISTENTES À Hemileia vastatrix Berg et Br.
}

\author{
Chemical composition of raw grains of cultivars the Coffea arabica $\mathbf{L}$. \\ susceptible and resistant to Hemileia vastatrix Berg et Br.
}

\author{
Luciana Maria Vieira Lopes Mendonça1, Rosemary Gualberto Fonseca Alvarenga Pereira², \\ Antônio Nazareno Guimarães Mendes ${ }^{3}$, Flávio Meira Borém ${ }^{4}$, Elizabeth Rosemeire Marques
}

\begin{abstract}
RESUMO
Com este trabalho, buscou-se caracterizar a composição química e físico-química dos grãos crus de 16 cultivares de café Coffea arabica $\mathrm{L}$., com o intuito de avaliar novos materiais desenvolvidos com resistência à ferrugem (Hemileia vastatrix $\mathrm{Berg}$. et $\mathrm{Br}$.) em comparação aos tradicionais. Desta forma, frutos provenientes do ensaio de melhoramento genético do MAPA/PROCAFE, localizado na Fazenda Experimental de Varginha em MG foram colhidos e transportados imediatamente para o Pólo de Tecnologia em PósColheita do Café da UFLA, onde foram lavados, descascados e secados em terreiro de concreto. Após o beneficiamento, os grãos foram acondicionados em latas de alumínio e armazenados a $15^{\circ} \mathrm{C}$. Os frutos avaliados correspondiam às cultivares 'Acaiá', 'Acauã', 'Bourbon Amarelo', 'Canário', 'Catuaí Amarelo', 'Catuaí Vermelho', 'Catucaí Amarelo', 'Catucaí Vermelho', 'Icatu Amarelo', 'Icatu Vermelho' 'Mundo Novo', 'Palma', 'Rubi', 'Sabiá 398', 'Siriema' e 'Topázio', do ano safra 2002. Os grãos crus foram moídos em moinho de bola com nitrogênio líquido. As análises realizadas foram: açúcares totais, redutores e não-redutores, extrato etéreo, polifenóis e cafeína. Diferenças foram consideradas significativas e as cultivares apresentaram variações para os teores de todos os compostos avaliados, indicando haver uma influência do genótipo sobre esses constituintes.
\end{abstract}

Termos para indexação: Café, composição química, cultivares, qualidade, grão cru.

\begin{abstract}
The aim of this article is characterizing the chemical and physical chemical composition of raw grains and analyzing new resistent material to rust (Hemilea vastatrix Berg. et Br.) compared to the traditional ones. The fruits were originated from breeding experiments from MAPA/PROCAFÉ, localized in the experimental farm of Varginha, Minas Gerais state. They were harvested and taken to the Postharvest Technology Center of Universidade Federal de Lavras, where they were washed, peeled and dried in a concrete ground. After cleaning, the grains were packed in aluminun box and stored at $15^{\circ} \mathrm{C}$. The utilized fruits cultivars were: 'Acaiá', 'Acauã', 'Bourbon Amarelo', 'Canário', 'Catuaí Amarelo', 'Catuaí Vermelho', 'Catucaí Amarelo', 'Catucaí Vermelho', 'Icatu Amarelo', 'Icatu Vermelho', 'Mundo Novo', 'Palma', 'Rubi', 'Sabiá 398', 'Siriema'e 'Topázio', from 2002 harvest. The raw beans were tritured in a ball mills with liquid $\mathrm{N}_{2}$. The accomplished analyses were: total sugars, reducers and non reducers, ethereal extract, polyphenols and caffeine. Differences were considered as significants and the cultivars showed variations related to tenors of all the evalued compositions, indicating to have influences of genotypo on these constituents.
\end{abstract}

Index terms: Coffee, chemical compositions, cultivars, quality, grain raw.

\section{(Recebido em 30 de abril de 2004 e aprovado em 7 de fevereiro de 2006)}

\section{INTRODUÇÃO}

A atividade cafeeira vem se adaptando nos últimos anos, para atender a demanda do mercado. Se por um lado grandes níveis de tecnologia têm sido exigidos pelo setor cafeeiro, para o aumento da produtividade, redução de custos e restrição ao uso de agroquímicos, por outro lado, nunca valorizou-se tanto a qualidade do café com a crescente expansão do consumo de cafés especiais.

Os programas de melhoramento genético do cafeeiro preocupam-se em apurar cultivares com características vegetativas associadas a um elevado potencial produtivo, possibilitando ainda a produção de cafés com menor custo e reduzida aplicação de agrotóxicos no controle de pragas e doenças. Por outro lado, é preciso unir a estas características ideais, a potencialidade de produção de cafés de qualidade, tanto do ponto de vista fitossanitário, quanto da bebida.

As cultivares Canário, Catucaí Vermelho, Catucaí Amarelo, Palma I e Sabiá foram recentemente lançadas com objetivo de serem materiais resistentes à ferrugem, e a cultivar Siriema com resistência múltipla ao bicho-mineirodo-cafeeiro e à ferrugem. Na Tabela 1, estão apresentados os cruzamentos realizados na obtenção destas cultivares.

\footnotetext{
${ }_{1}^{1}$ Dra. em Ciência dos Alimentos, Eng. Agrônoma, Escola Agrotécnica Federal de Muzambinho - luciana@eafmuz.gov.br.

2 Dra, Farmacêutica, Professora Adjunto do Departamento de Ciência dos Alimentos/DCA da Universidade Federal de Lavras/UFLA - Cx. P. 3037 37200-000 - Lavras/MG - rosegfa@ufla.br.

${ }^{3}$ Dr. Engenheiro Agrícola, Prof. Adjunto Departamento de Engenharia/DEG da Universidade Federal de Lavras/UFLA - borem@ufla.br.

${ }^{4}$ Dr. Engenheiro Agrônomo, Professor Adjunto Departamento de Agricultura/DAG da Universidade Federal de Lavras/UFLA - nazareno@ufla.br

${ }^{5}$ Agrônoma, Mestranda em Ciência dos Alimentos na Universidade Federal de Lavras/UFLA
} 
TABELA 1 - Cruzamentos realizados para obtenção dos materiais resistentes à ferrugem (Hemileia vastatrix Berg et Br).

\begin{tabular}{lccc}
\hline & Cultivares & & Material obtido \\
\hline Icatu & $\mathrm{X}$ & Catuaí amarelo & Catucaí amarelo \\
Icatu & $\mathrm{X}$ & Catuaí vermelho & Catucaí vermelho \\
Catuaí vermelho & $\mathrm{X}$ & Catimor & IBC- Palma 1 \\
Acaiá & $\mathrm{X}$ & Catimor & Sabiá \\
Mundo novo & $\mathrm{X}$ & Sarchimor & Acauã \\
Catuaí amarelo & $\mathrm{X}$ & Híbrido de Timor & Canário \\
Coffea racemosa & $\mathrm{X}$ & Coffea arabica & Siriema \\
\hline
\end{tabular}

Na obtenção destas cultivares, os melhoristas utilizaram materiais da espécie Coffea canephora Pierre. Estes cafés são conhecidos por apresentarem uma qualidade inferior da bebida, em relação aos cafés da espécie Coffea arabica L., devido a diferenças na composição química dos grãos.

A composição química dos grãos é influenciada por fatores genéticos, ambientais e culturais, pelos métodos de colheita, processamento, armazenamento, torração e moagem, que podem afetar diretamente a qualidade da bebida do café. A Associação Brasileira das Indústrias do Café (ABIC) afirma que não só o beneficiamento ou os cuidados na torra e moagem, ou um blend cuidadosamente estudado e controlado, fazem a qualidade da bebida café. A origem genética dos grãos é tão decisiva quanto todos os outros cuidados que permeiam a produção, do pé de café à xícara do consumidor (QUALIDADE..., 1999).

Entre os açúcares presentes nos grãos de café, a sacarose destaca-se como sendo aquele encontrado em maior quantidade e sua quantificação pode variar entre espécies, origem e tipo de processamento. Rogers et al. (1999) observaram o dobro de sacarose em grãos de café arábica maduros, em relação ao café robusta.

Os óleos têm importante papel na retenção do flavour do café torrado, e devido aos altos teores em que são encontrados nos grãos, são objetos de vários estudos (CARRERA et al., 1998; GONZÁLEZ et al., 2001).

Os compostos fenólicos estão presentes no grão de café em grandes proporções. Sua função tem sido associada à inibição de insetos e pragas, e quando encontrados em grandes proporções, são associados à perda de qualidade do café (CLIFFORD, 1985). Martín et al. (1998) estudaram os teores de polifenóis e do ácido clorogênico em cafés Arábica e Robusta. Foram claramente detectados valores superiores destes dois compostos no café Robusta.
Casal et al. (2000) avaliaram o teor de cafeína das espécies Arábica e Robusta e observaram que, tanto nos grãos crus como nos torrados, os Robustas contêm maiores quantidades deste composto.

Grãos despolpados de espécies selvagens de $C$. arabica, originadas da Etiópia e do Quênia e de $C$. canephora, cultivadas em cinco países africanos, foram avaliados por Ky et al. (2001), com o objetivo de determinar as diferenças para os teores de sacarose, trigonelina, cafeína e ácido clorogênico. Os genótipos de $C$. arabica apresentaram maiores teores de sacarose e trigonelina e, nos genótipos de C. canephora, foram encontrados os maiores valores para a cafeína e ácido clorogênico.

O conhecimento do potencial de produção de cafés de qualidade das cultivares melhoradas geneticamente é uma ferramenta para complementar os trabalhos de melhoramento genético. Lopes (2000) avaliou alguns constituintes químicos dos grãos crus de uma mistura de frutos de oito cultivares de C. arabica L. e observou variações significativas nos teores de sólidos solúveis, extrato etéreo, açúcares e proteína bruta. $\mathrm{O}$ autor ressalta a correlação destes constituintes com a qualidade de bebida, por serem estes compostos os precursores das substâncias responsáveis pelo sabor e aroma da bebida do café.

Em estudos realizados sobre as características químicas de 15 das principais cultivares e linhagens do café tipo arábica lançadas pelo IAC e cultivadas naquela região, Aguiar (2001) observou diferenças estatísticas significativas para os teores de sacarose, proteína, ácido clorogênico, trigonelina e cafeína.

Com o presente trabalho, objetivou-se avaliar a composição química dos grãos crus de 16 cultivares de café, com o intuito de verificar a influência da espécie Coffea canephora, utilizada na obtenção de nove destas cultivares, com resistência à ferrugem. 


\section{MATERIAL E MÉTODOS}

\section{Caracterização do experimento}

Os grãos das cultivares de cafeeiro com resistência à ferrugem: 'Sabiá 398', 'Siriema', 'Icatu Amarelo', 'Icatu Vermelho', 'Canário', 'Palma I', 'Catucaí Amarelo', 'Catucaí Vermelho', 'Acauã' e das cultivares suscetíveis: 'Rubi', 'Catuaí Amarelo', 'Catuaí Vermelho', 'Topázio', 'Bourboun Amarelo', 'Acaiá' e 'Mundo Novo', pertencentes ao ensaio de melhoramento genético da Fazenda Experimental de Varginha, localizada na região Sul de Minas Gerais, coordenado pelo Ministério da Agricultura Pecuária e Abastecimento (MAPA/PROCAFÉ) foram os objetos desse estudo. Na Figura 1 encontram-se apresentados as informações climáticas dos meses de janeiro a junho de 2002 segundo Fundação Procafé (2002).

Para o experimento, foram colhidos, por derriça manual no pano, aproximadamente 25 litros de café por cultivar em 11 de junho de 2002. O material foi transportado para o Pólo de Tecnologia em Pós-colheita do Café do Centro de Ensino Pesquisa e Extensão do Agronegócio Café (CEPECAFÉ) da Universidade Federal de Lavras, onde foi imediatamente lavado. Os frutos bóia de cada parcela foram separados por imersão do café em uma caixa d'água de 1000 litros e retirados com o auxílio de uma peneira. O restante do material foi processado em um descascador manual.

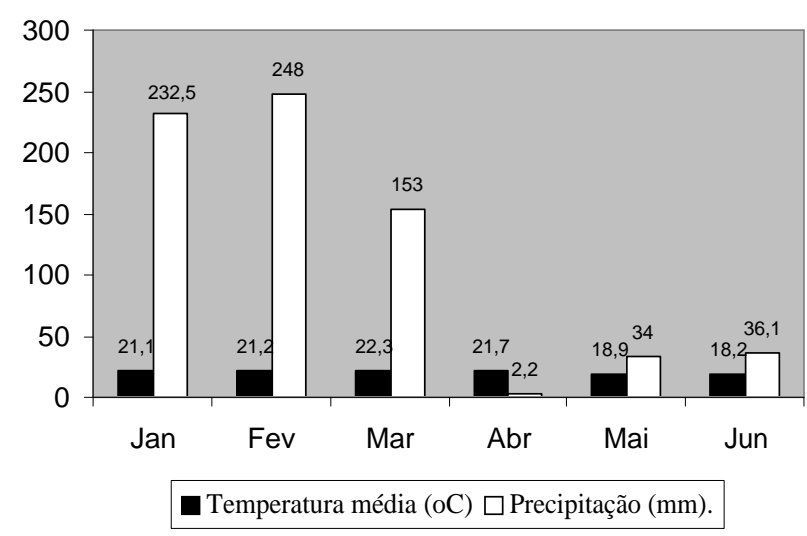

FIGURA 1 - Informações climatológicas da Fazenda Experimental de Varginha - Fundação Procafé (FUNDAÇÃO PROCAFÉ, 2002).

O café foi levado à secagem em terreiro de concreto durante 11 dias, manuseado em camadas bem finas, sendo revolvido, em média, sete vezes ao dia no sentido da sombra e, a partir da meia seca, amontoado e coberto com lona plástica à tarde. $\mathrm{O}$ processo foi interrompido quando os grãos apresentaram um teor médio de umidade de $12 \%$.
O café em pergaminho permaneceu armazenado em latas de alumínio, em sala refrigerada $\mathrm{a} \pm 15^{\circ} \mathrm{C}$, por dois meses, quando foi beneficiado e homogeneizado. $\mathrm{O}$ volume de café de cada cultivar foi dividido em três partes iguais, constituindo as três repetições. As amostras permaneceram armazenadas nesta sala, nas mesmas condições, enquanto se procedia ao preparo das amostras.

\section{Preparo das amostras}

As etapas subseqüentes que envolveram o preparo e as avaliações propostas foram realizadas no Pólo de Tecnologia em Qualidade do Café da UFLA. Amostras de grãos crus e torrados das 16 cultivares foram avaliadas, das quais foram retirados todos os defeitos extrínsecos e extrínsecos do café segundo Brasil (2003). As amostras foram moídas durante 3 minutos, em moinho de bola, com nitrogênio líquido. Após a moagem, o material foi acondicionado em embalagens de PVC e armazenado em freezer, com temperatura aproximada de $-18^{\circ} \mathrm{C}$.

\section{Análises físico-químicas e químicas}

Açúcares totais, redutores e não-redutores: Os açúcares foram extraídos pelo método de Lane-Enyon, citado pela AOAC (1990) e determinados pela técnica de Somogy, adaptada por Nelson (1944).

Extrato etéreo: foi obtido por extração com éter etílico, por 5 horas, em aparelho do tipo Soxhlet, da Tecnal, segundo normas da AOAC (1990).

Polifenóis: foram extraídos à quente, pelo método de Goldstein \& Swain (1963) utilizando metanol (50\%) como extrator e quantificados pelo método de Folin Denis, descrito pela AOAC (1990).

Cafeína: foi extraída segundo o $1^{0}$ Método descrito pelo Instituto Adolfo Lutz (1985) e a determinação realizada por espectrofotometria.

\section{Delineamento experimental e análise estatística}

O experimento foi montado considerando 16 cultivares (tratamentos) com 3 repetições. A análise de variância foi realizada pelo software SISVAR (FERREIRA, 2003.), e os dados foram submetidos ao Teste de ScottKnott, a 5\% de significância.

\section{RESULTADOS E DISCUSSÃO}

\section{Açúcares totais, redutores e não-redutores}

O resumo da análise de variância dos teores médios de açúcares totais, não-redutores e redutores das 16 cultivares avaliadas, encontra-se na Tabela 2. 
Pelos resultados apresentados na Tabela 3, é possível observar que as cultivares Acaiá, Bourbon Amarelo, Catuaí Amarelo, Catuaí Vermelho, Rubi e Sabiá tiveram, em seus grãos crus, os maiores valores de açúcares totais. Nenhuma das cultivares que se destacam pela resistência à ferrugem (Hemileia vastatrix Berg et Ber.) participa deste grupo, por ser essa uma característica que pode ter sido herdada dos cafés robustas, que possuem menores teores destes constituintes.
Maiores concentrações de açúcares no grão cru permitem um aumento na participação destes compostos nas reações do processo de torração. Substâncias voláteis são formadas a partir da combinação dos açúcares com as proteínas, que são responsáveis, em grande parte, pelo aroma do café (ILLY \& VIANI, 1995). Isso é um indicativo de que a disponibilidade deste substrato aumenta a produção destes compostos.

TABELA 2 - Resumo da análise de variância para os teores de açúcares totais, não-redutores e redutores dos grãos crus de 16 cultivares de Coffea arabica L.

\begin{tabular}{|c|c|c|c|c|}
\hline \multirow[b]{2}{*}{ F.V. } & \multirow[b]{2}{*}{ G.L. } & \multicolumn{3}{|c|}{ Quadrados médios e significâncias } \\
\hline & & Açúcares totais & $\begin{array}{l}\text { Açúcares não } \\
\text { redutores }\end{array}$ & Açúcares redutores \\
\hline Cultivar & 15 & $1,525146^{*}$ & $1,369573 *$ & $0,806648 *$ \\
\hline Erro & 32 & 0,576256 & 0,564769 & 0,087758 \\
\hline C.V. $(\%)$ & --- & 7,89 & 9,70 & 15,80 \\
\hline
\end{tabular}

* significativo, a $5 \%$ de probabilidade, pelo teste de F.

TABELA 3 - Valores médios dos açúcares totais (\% M.S.), açúcares não-redutores e redutores de grãos crus de 16 cultivares de Coffea arabica L.

\begin{tabular}{|c|c|c|c|c|c|c|c|c|}
\hline \multirow{9}{*}{ 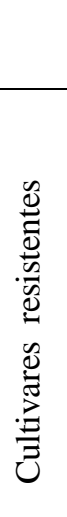 } & \multirow{2}{*}{$\begin{array}{l}\text { Cultivares } \\
\text { Acauã }\end{array}$} & \multicolumn{2}{|c|}{$\begin{array}{l}\text { Açúcares totais } \\
(\% \text { M. S.) }\end{array}$} & \multicolumn{2}{|c|}{$\begin{array}{c}\text { Açúcares não } \\
\text { redutores (\% M. S.) }\end{array}$} & \multicolumn{3}{|c|}{$\begin{array}{c}\text { Açúcares redutores } \\
(\% \text { M. S. })\end{array}$} \\
\hline & & 9,28 & $\mathbf{b}$ & 7,21 & b & 2,07 & $\mathbf{a}$ & \\
\hline & Canário & 8,57 & b & 7,02 & b & 1,55 & & b \\
\hline & Catucaí Amarelo & 8,55 & $\mathbf{b}$ & 7,03 & $\mathbf{b}$ & 1,52 & & b \\
\hline & Catucaí Vermelho & 9,44 & b & 7,82 & & 1,61 & & b \\
\hline & Icatu Amarelo & 9,51 & b & 7,02 & b & 2,50 & $\mathbf{a}$ & \\
\hline & Icatu Vermelho & 9,67 & b & 8,43 & & 1,24 & & c \\
\hline & Palma I & 9,22 & $\mathbf{b}$ & 7,41 & $\mathbf{b}$ & 1,81 & & b \\
\hline & Sabiá 398 & 10,65 & $\mathbf{a}$ & 8,45 & & 2,20 & $\mathbf{a}$ & \\
\hline & Siriema & 9,71 & b & 7,61 & b & 2,10 & $\mathbf{a}$ & \\
\hline & Acaiá & 10,01 & $\mathbf{a}$ & 7,47 & b & 2,54 & $\mathbf{a}$ & \\
\hline$\stackrel{0}{2}$ & Bourboun Amarelo & 10,45 & $\mathbf{a}$ & 8,58 & & 1,87 & & b \\
\hline$\underbrace{}_{\mathscr{N}}$ & Catuaí Amarelo & 10,26 & $\mathbf{a}$ & 8,86 & & 1,40 & & b \\
\hline $\begin{array}{l}\bar{n} \\
\tilde{\omega}\end{array}$ & Catuaí Vermelho & 10,26 & $\mathbf{a}$ & 7,97 & & 2,29 & $\mathbf{a}$ & \\
\hline$\stackrel{\text { जै }}{\geq}$ & Mundo Novo & 9,37 & b & 8,58 & & 0,79 & & c \\
\hline 夏 & Rubi & 10,59 & $\mathbf{a}$ & 7,86 & & 2,72 & $\mathbf{a}$ & \\
\hline & Topázio & 8,46 & b & 6,68 & b & 1,79 & & b \\
\hline
\end{tabular}

* médias seguidas pela mesma letra na coluna, não diferem entre si, a 5\% de probabilidade, pelo teste de Scott-Knott. 
Lopes (2000) estudou seis dessas 16 cultivares avaliadas, contudo, os grãos provinham de uma mistura de frutos. Os valores encontrados pelo autor, para os grãos crus das cultivares Icatu Amarelo, Mundo Novo e Topázio foram de 9,44\%, 9,55\% e 8,72\%, respectivamente. Estes teores são muito próximos aos detectados para essas mesmas cultivares, no presente estudo, que na mesma ordem de apresentação foram: $9,51 \%, 9,37 \%$ e $8,46 \%$. As três outras cultivares, Catuaí Vermelho, Catuaí Amarelo e Rubi, tiveram neste trabalho, valores superiores aos observados nos grãos provenientes da mistura de frutos. Esses valores mais elevados de açúcares podem ter sido favorecidos pela presença única de frutos cerejas, nos quais há maior teor destes carboidratos, conforme cita Pimenta (1995).

As cultivares diferenciam-se quanto aos teores de açúcares totais quando analisados no grão cru, sendo as cultivares de café originárias de arábica, superiores aquelas que tem o robusta como progenitor. As cultivares 'Bourbon Amarelo', 'Catuaí Amarelo', 'Catuaí Vermelho', 'Catucaí Vermelho', 'Icatu Vermelho', 'Mundo Novo', 'Rubi'e ‘Sabiá' destacam-se com os maiores valores de açúcares não-redutores.

Uma possível relação existente entre o tipo de processamento e a origem genética, pode ser observada, considerando a proximidade dos dados obtidos por Villela (2002) para grãos da cultivar Rubi, obtidos pelo mesmo processamento.

Os grãos das cultivares 'Acaiá', 'Acauã', 'Catuaí Vermelho', 'Icatu Amarelo', 'Rubi', 'Sabiá' e 'Siriema', exibiram os maiores teores dos açúcares redutores.

Valores mais elevados destes açúcares foram associados por Pimenta (1995) ao aumento do nível de maturação dos frutos, sendo os cerejas com maior percentual. A glicose e a frutose são, entre os açúcares redutores, encontrados em maior quantidade em grãos crus, conforme indicam Rogers et al. (1999), que observaram ainda que, no início da maturação dos frutos, são esses os açúcares predominantes.

\section{Extrato etéreo, polifenóis e cafeína}

A partir da análise de variância (Tabela 4), observase que as cultivares apresentam diferenças significativas para os teores de extrato etéreo, polifenóis e cafeína.

Os valores médios de extrato etéreo (Tabela 5) indicam que as cultivares Acauã, Catuaí Vermelho, Catucaí Amarelo, Mundo Novo e Palma I têm em seus grãos crus, maior riqueza destes compostos. O menor teor foi observado para 'Bourbon Amarelo' que apresentou aproximadamente $3,79 \%$ a menos de extrato etéreo que o maior valor encontrado, para a cultivar Catucaí Amarelo.
Valores bem inferiores foram observados por Lopes (2000), contudo, entre o grupo de cultivares estudadas, 'Mundo Novo' apresentou os maiores teores. Essas diferenças referem-se, possivelmente, a diferenças com relação à homogeneidade do grau de maturação dos frutos, maior no presente trabalho, como resultado do uso do processo de descascamento no preparo destes cafés.

Esses dados, de qualquer forma, indicam que diferenças interespecíficas existem e que algumas cultivares de arábica e/ou de robusta podem apresentar teores de extrato etéreo, abaixo ou acima do normalmente verificado nestas espécies.

Em estudos da OIC (1991), as cultivares Catuaí Amarelo e Mundo Novo apresentaram diferenças quanto ao teor de lipídeos, que também mostrou variação para o tipo de processamento.

Na avaliação dos teores de polifenóis, as cultivares Acaiá, Acauã, Canário, Catuaí Amarelo, Catucaí Amarelo, Icatu Amarelo e Topázio apresentaram os maiores teores.

Com exceção das cultivares Acaiá, Catuaí e Topázio, as outras quatro são consideradas materiais resistentes à ferrugem. As cultivares de café robusta são reconhecidas por conterem maiores teores de polifenóis, o que está associado à resistência destas plantas à ferrugem.

Villela (2002) encontrou valores de 7,31\%, 7,54\%, $7,55 \%$ e $7,73 \%$ para cafés despolpados, descascados, desmucilados e natural, da cultivar Rubi. Esses valores superiores ao encontrado para a mesma cultivar, que foi de $6,58 \%$ podem estar associados à presença dos defeitos, que o autor não retirou das amostras e que favorecem a elevação dos teores destes compostos.

No café estritamente mole avaliado por Coelho (2000), foram encontrados cerca de 7,00\% de polifenóis. Considerando a qualidade superior da bebida originada por este café, e a proximidade dos valores obtidos nesta avaliação das cultivares, é possível sugerir que estas progênies resultarão em bebidas de excelente qualidade.

Com relação aos teores de cafeína, no grão cru, os maiores valores foram encontrados nos grãos das cultivares 'Catucaí Amarelo‘, 'Catucaí Vermelho', 'Icatu Amarelo', 'Icatu Vermelho', 'Mundo Novo', 'Palma I', 'Rubi' e 'Sabiá'. As demais cultivares apresentaram os menores valores e não diferiram.

Esperava-se que todas as cultivares originadas de cruzamentos com a espécie robusta apresentassem maiores teores de cafeína, considerando que essa espécie apresenta quase o dobro do previsto em cafés arábicas'. Contudo, 'Mundo Novo' e 'Rubi', cultivares $100 \%$ arábica, também tiveram os maiores teores deste alcalóide. 
TABELA 4 - Resumo da análise de variância para os teores de extrato etéreo, polifenóis e cafeína, de grãos crus de 16 cultivares de Coffea arabica L.

\begin{tabular}{|c|c|c|c|c|}
\hline \multirow{2}{*}{ F.V. } & \multirow{2}{*}{ G.L. } & \multicolumn{3}{|c|}{ Quadrados médios e significâncias } \\
\hline & & Extrato etéreo & Polifenóis & Cafeína \\
\hline Cultivar & 15 & $2,994831 *$ & $0,633961 *$ & $0,018892^{*}$ \\
\hline Erro & 32 & 0,370323 & 0,100198 & 0,006960 \\
\hline C.V. (\%) & --- & 3,94 & 4,51 & 7,64 \\
\hline
\end{tabular}

* significativo, a $5 \%$ de probabilidade, pelo teste de $\mathrm{F}$.

TABELA 5 - Valores médios dos teores de extrato etéreo, polifenóis e cafeína, de grãos crus de 16 cultivares de Coffea arabica $\mathrm{L}$.

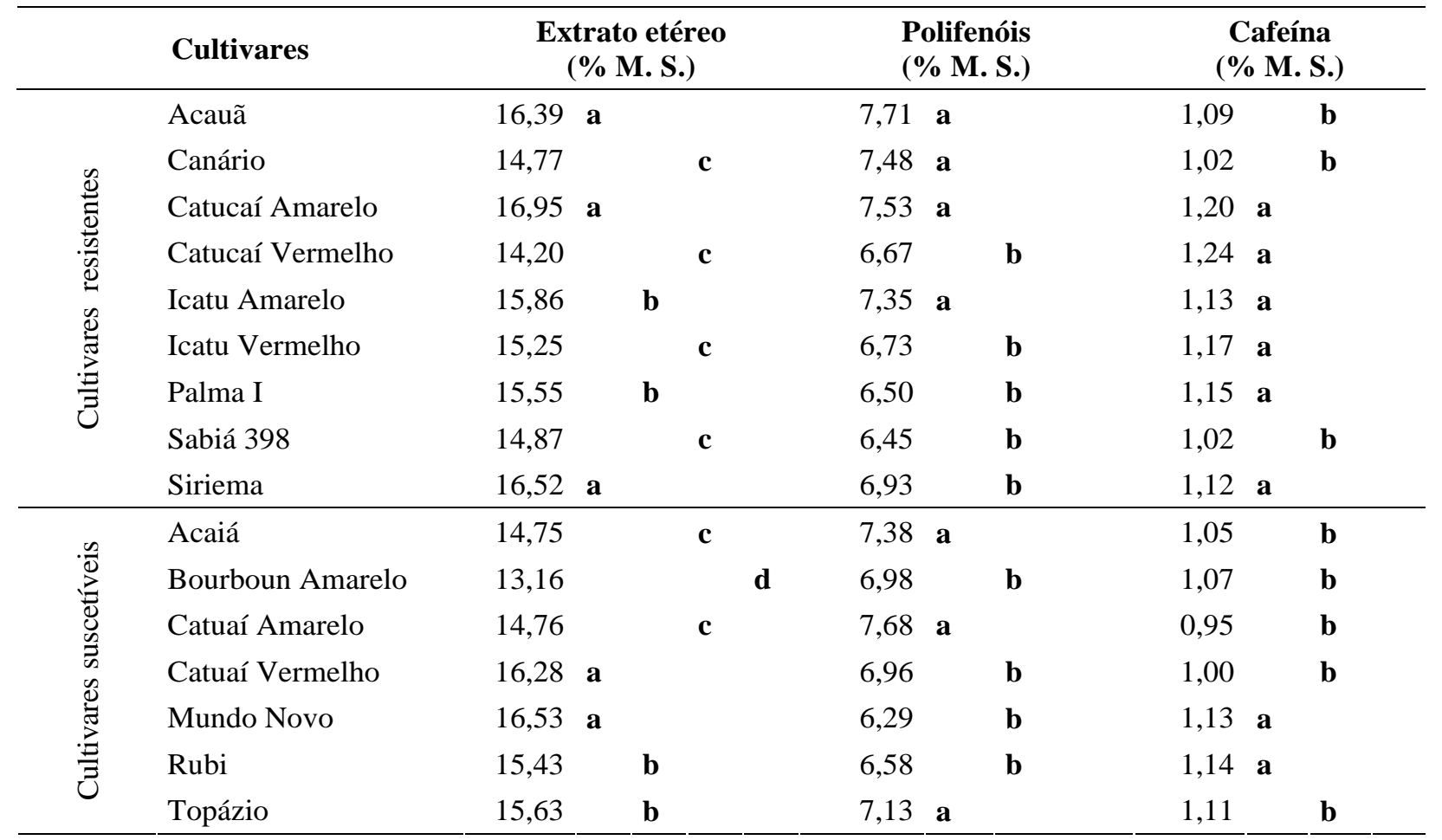

* médias seguidas pela mesma letra na coluna, não diferem entre si, a 5\% de probabilidade, pelo teste de Scott-Knott.

Charrier \& Berthaud (1975) afirmam que ocorre uma expressão diferenciada do genótipo para a síntese de cafeína, a qual varia de uma espécie para outra e que ocorre influência da interação entre o genótipo e o ambiente. Esses podem ser os motivos para a obtenção desta variação que contrariou as expectativas com relação ao teor da cafeína e as cultivares relacionadas com a espécie robusta.

Villela (2002) observou não haver influência do tipo de processamento e o teor de cafeína, para a cultivar Rubi, para a qual foram detectados valores entre $0,90 \%$ a $0,95 \%$.
Estes valores, inferiores aos 1,15\% obtidos, podem confirmar a afirmativa dos autores citados, visto que ambas as cultivares são provenientes de diferentes locais de cultivo.

\section{CONCLUSÕES}

Os resultados experimentais obtidos no presente trabalho permitiram concluir que as cultivares avaliadas apresentam diferenças na composição química dos grãos crus, sendo possível inferir que existe uma influência do genótipo sobre essas características. 


\section{REFERÊNCIAS BIBLIOGRÁFICAS}

AGUIAR, A. T. da E. Descritores para caracterização de cultivares e linhagens de café tipo arábica. $2001.98 \mathrm{f}$. Dissertação (Mestrado em Melhoramento Genético Vegetal) - Universidade Estadual de Campinas, Campinas, 2001.

ASSOCIATION OF OFFICIAL ANALYTICAL CHEMISTS. Official methods of analysis of the Association of Official Analytical Chemists. 15. ed. Washington, 1990. 2 v.

BRASIL. Ministério da Agricultura, Pecuária e Abastecimento. Instrução Normativa $n^{\circ} 8$, de 11 de junho de 2003. Diário Oficial da República Federativa do Brasil, Brasília, p. 22-29, 20 ago. 2003. Seção 1.

CASAL, S.; OLIVEIRA, M. B.; FERREIRA, M. A. HPLC/ diode-array applied to the thermal degradation of trigonelline, nicotinic acid and caffeine in coffee. Food Chemistry, Oxford, v. 68, n. 4, p. 481-485, Mar. 2000.

CARRERA, F. et al. Authentication of green coffee varieties according to their sterolic profile. Analytica Chimica Acta, [S.1.], v. 370, p. 131-139, 1998.

CHARRIER, A.; BERTHAUD, J. Variation de la teneur en caféine dans le genre Coffea. Café Cacao Thé, Paris, v. 11, n. 4, p. 251-264, oct./déc. 1975.

CLIFFORD, M. N. Chemical and physical aspects of green coffee and coffee products. In: CLIFFORD, M. N.; WILLSON, K. C. (Eds.). Coffee: botany, biochemistry and production of beans ans beverage. New York: Croom Helm, 1985. p. 305-374.

COELHO, K. F. Avaliação química e sensorial da qualidade do café de bebida estritamente mole após a s inclusão de grãos defeituosos. 2000. 96 p. Dissertação (Mestrado em Ciência dos Alimentos) - Universidade Federal de Lavras, Lavras, 2000.

FERREIRA, D. F. Programa Sisvar.exe Sistema de Análise de Variância. Versão 4.3. Lavras: UFLA, 2003.

FUNDAÇÃO PROCAFÉ. Boletim de avisos. Varginha, 2002.

GOLDSTEIN, J. L.; SWAIN, T. Changes in tannins in ripening fruits. Phytochemistry, Oxford, v. 2, n. 4, p. 371382, Dec. 1963.

GONZÁLEZ, A. G. et al. HPLC analysis of tocopherols and triglycerides in coffee and their use as authentication parameters. Food Chemistry, London, n. 75, p. 93-101, 2001.
ILLY, A.; VIANI, R. Espresso coffee: the chemistry of quality. San Diego: [s.n.], 1995. 253 p.

INSTITUTO ADOLFO LUTZ. Normas analíticas, métodos químicos e físicos para análise de alimentos. 3. ed. São Paulo, 1985. v. 1.

KY, C. L. et al. Caffeine, trigonelline, chlorogenic acids and sucrose diversity in wild Coffea arabica L. and $C$. canephora P. acessions. Food Chemistry, London, n. 75, p. 223-230, 2001.

LOPES, L. M. V. Avaliação da qualidade de grãos crus e torrados de cultivares de cafeeiro (Coffea arabica $\mathbf{L}$.). 2000. 95 p. Dissertação (Mestrado em Ciência dos Alimentos) - Universidade Federal de Lavras, Lavras, 2000.

MARTIN, M. J.; PABLOS, F.; GONZÁLEZ, A. G. Characterization of green coffee varieties according to their metal content. Analytica Chimica Acta, [S.1.], v. 358, p. 177183, 1998.

NELSON, N. A photometric adaptation of Somogy method for the determination of glucose. Journal of Biological Chemists, Baltmore, v. 153, n. 1, p. 375-384, 1944.

ORGANIZACION INTERNACIONAL DEL CAFÉ. Quantitiative descriptive flavours profiling of coffees form COOPARAÍSO - MG, Brasil. Londres, 1991. Não paginado (Reporte de Evaluación Sensorial).

PIMENTA, C. J. Qualidade do café (Coffea arabica $L$.) originado de frutos colhidos de quatro estádios de maturação. 1995. 94 f. Dissertação (Mestrado em Ciência dos Alimentos) - Universidade Federal de Lavras, Lavras, 1995.

QUALIDADE no pé. Jornal do Café, Rio de Janeiro, v. 8, n. 91, p. 18-19, mar. 1999.

ROGERS, W. J. et al. Changes to the content of sugars, sugar alcohols, myo-inositol, carboxilic acids and inorganic anions in development grains from different varieties of Robusta (Coffea canephora) and arabica (C. arabica) coffees. Plant Science, London, v. 149, p. 115-123, 1999.

VILLELA, T. C. Qualidade do café cereja despolpado, desmucilado, descascado e natural, durante o processo de secagem. 2002. 69 p. Dissertação (Mestrado em Ciência dos Alimentos) - Universidade Federal de Lavras, Lavras, 2002. 